\title{
Determination of selenium by X-ray fluorescence spectrometry using dispersive solid-phase microextraction with multiwalled carbon nanotubes as solid sorbent
}

\author{
Robert Skorek, ${ }^{a}$ Edyta Turek, ${ }^{a}$ Beata Zawisza, ${ }^{a}$ Eva Marguí, ${ }^{b}$ Ignasi Queralt, ${ }^{c}$ Marek Stempin, ${ }^{d}$ \\ Piotr Kucharski ${ }^{d}$ and Rafal Sitko ${ }^{* a}$
}

Received 7th June 2012, Accepted 19th July 2012

DOI: $10.1039 / \mathrm{c} 2 \mathrm{ja30179b}$

\begin{abstract}
A dispersive solid-phase microextraction (DSPME) with multiwalled carbon nanotubes (MWCNTs) as solid sorbent and ammonium pyrrolidinedithiocarbamate (APDC) as chelating agent was developed for determination of selenium. In the proposed procedure, the Se(Iv)-APDC complex is adsorbed on MWCNTs dispersed in aqueous samples. After the adsorption process, the aqueous samples are filtered and MWCNTs with selenium chelate are collected onto a filter. The loaded filters are directly measured using X-ray fluorescence (XRF) spectrometry. In order to obtain high recovery of the Se ions on MWCNTs, the proposed procedure was optimized for various analytical parameters such as $\mathrm{pH}$, amounts of MWCNTs and APDC, sample volume and time of the sorption process. Under optimized conditions Se ions can be determined with very good recovery $(97 \pm 3 \%)$, precision $(\mathrm{RSD}=3.2 \%)$ and detection limits (from 0.06 to $0.2 \mathrm{ng} \mathrm{mL}^{-1}$, depending on counting time and XRF equipment). The effect of common coexisting ions was also investigated. Se(Iv) can be determined in the presence of heavy metal ions and alkali metals. The chemical interferences observed for high concentrations of $\mathrm{Cu}(\mathrm{II}), \mathrm{Fe}(\mathrm{III})$, and $\mathrm{Zn}$ (II) can be completely eliminated using precipitation with $\mathrm{NaOH}$. The proposed method was applied for the determination of Se in mineral water and biological samples (Lobster Hepatopancreas). The proposed method can also be applied for selenium speciation. The concentration of selenate can be obtained as the difference between the concentration of selenite after and before prereduction of selenate to selenite.
\end{abstract}

\section{Introduction}

Selenium is an essential nutrient for living organisms, necessary also for human beings. However, the difference between the nutritious requirement and the toxic dose is small. ${ }^{1}$ For this reason, the development of reliable and simple analytical methods for the determination of selenium in environmental and biological samples is necessary. Moreover, the toxicity of Se depends on its chemical forms. The best known species are two oxyanions, selenite $\left(\mathrm{SeO}_{3}{ }^{2-}\right.$ or $\left.\mathrm{Se}(\mathrm{IV})\right)$ and selenate $\left(\mathrm{SeO}_{4}{ }^{2-}\right.$ or $\mathrm{Se}(\mathrm{vI})$ ), and some organic species. The Se species most frequently found in waters and environmental samples are $\mathrm{Se}$ (IV) and $\mathrm{Se}(\mathrm{VI})$, and $\mathrm{Se}(\mathrm{VI})$ is more toxic than $\mathrm{Se}(\mathrm{IV}){ }^{2}{ }^{2}$ Thus, it is important not only to determine the total Se concentration but also the concentration of each species. Analytical methods for the

${ }^{a}$ Institute of Chemistry, University of Silesia, Szkolna 9, 40-006 Katowice, Poland.E-mail: rafal.sitko@us.edu.pl

${ }^{b}$ Department of Chemistry, University of Girona, Campus Montilivi s/n, 17170-Girona, Spain

"Institute of Earth Sciences "Jaume Almera", CSIC. Solé Sabarís s/n, 08028 Barcelona, Spain

${ }^{d}$ Central Mining Institute, Plac Gwarkow 1, 40-166, Katowice, Poland speciation of selenium have been reviewed..$^{2-4}$ The determination of Se in environmental samples is usually hampered because of the low concentration which is close to or below the detection limits of the most commonly used analytical methods. Thus, a preconcentration step is often required in order to improve limits of detection using e.g. solid-phase extraction (SPE), solid-phase microextraction (SPME) or co-precipitation. ${ }^{2}$ These methods are applied in matrix-Se separation as well. Hydride generation (HG) coupled with AAS, ICP-AES, and AFS techniques commonly applied for sensitive determination of $\mathrm{Se}^{5}$ often requires elimination of chemical interferences from the transition metal using co-precipitation, liquid-liquid extraction, masking agents, and ion-exchange procedures. ${ }^{6,7}$

One of the most widely used chelating agents for preconcentration and speciation of Se using liquid-liquid or solid-phase extraction techniques is ammonium pyrrolidinedithiocarbamate (APDC). APDC is usually applied for Se(Iv) co-precipitation, ${ }^{\mathbf{8}, 9}$ $\mathrm{SPE}^{10-12}$ or flow injection on-line sorption. ${ }^{13}$ APDC is also used in separation and preconcentration of $\mathrm{Se}$ (IV) using modern miniaturized preconcentration techniques such as cloud point extraction, ${ }^{14}$ dispersive liquid-liquid microextraction ${ }^{15-18}$ and single drop microextraction. ${ }^{19}$ These micro-preconcentration 
techniques can be combined with a spectroscopy technique which requires only a few microliters of organic phase to perform a measurement, e.g. electrothermal atomic absorption spectrometry, ${ }^{15,16}$ electrothermal vaporization-inductively coupled plasma-mass spectrometry, ${ }^{14,19}$ total-reflection X-ray fluorescence spectrometry ${ }^{17}$ or energy-dispersive X-ray fluorescence (EDXRF) spectrometry. ${ }^{18}$ APDC is noted for selectivity in the formation of complexes with $\mathrm{Se}(\mathrm{IV})$ and simultaneously very low stability of the complexes with $\mathrm{Se}(\mathrm{VI}) .{ }^{16}$ Therefore, Se(IV) species can be separated and determined without the interference of $\mathrm{Se}(\mathrm{vI})$. In this way, $\mathrm{Se}(\mathrm{IV})$ is determined directly and total inorganic Se concentration is evaluated after reduction of $\mathrm{Se}(\mathrm{VI})$ to

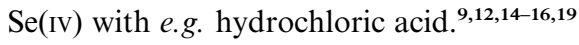

The determination of trace and ultratrace amounts of Se using SPE with or without chelating agent requires using a suitable solid sorbent: non-polar (C-18) sorbent, ${ }^{10,11,20}$ nano- $\mathrm{Al}_{2} \mathrm{O}_{3},{ }^{21}$ modified activated carbon, ${ }^{22}$ cetyltrimethylammonium bromide (CTAB)-modified alkyl silica, ${ }^{23}$ Dowex $1 \mathrm{X} 2$ resin, ${ }^{24}$ Diaion HP$2 \mathrm{MG}^{12}$ dithiocarbamate loaded polyurethane foam ${ }^{25}$ or dithizone sorbent. ${ }^{26}$ In this paper, the preconcentration of Se using multiwalled carbon nanotubes (MWCNTs) as solid sorbent and APDC as chelating agent is proposed. Although MWCNTs are commonly used for the preconcentration of metal ions, they have not been yet applied in preconcentration of $\mathrm{Se}^{27-29}$ The proposed procedure is based on dispersive solid-phase microextraction (DSPME). MWCNTs are dispersed in aqueous samples, which promotes the immediate interaction between the metal chelates and MWCNTs and shortens the time of sample preparation in comparison with a classical SPE. After the adsorption process, the MWCNTs with adsorbed Se(Iv)-APDC complex were collected onto a filter and measured directly using X-ray fluorescence (XRF) spectrometry without the necessity of analyte elution.

\section{Experimental section}

\section{Reagents}

Stock solutions of Se (1 mg mL $\left.{ }^{-1}\right)$, nitric acid (65\%, Suprapur $\left.{ }^{\circledR}\right)$, and ammonium hydroxide solution $\left(25 \%\right.$, Suprapur $\left.{ }^{\circledR}\right)$ were purchased from Merck (Darmstadt, Germany), and ammonium pyrrolidinedithiocarbamate $(>98 \%)$ was purchased from POCh (Gliwice, Poland). MWCNTs with diameters of 6-9 nm and lengths of $c a .5 \mu \mathrm{m}$ were purchased from Sigma-Aldrich (Steinheim, Germany). Before use, MWCNTs were refluxed with concentrated nitric acid, washed with high purity water until neutral $\mathrm{pH}$ was reached and then dried at $100^{\circ} \mathrm{C}$. The suspension of MWCNTs ( $5 \mathrm{mg} \mathrm{mL}^{-1}$ ) was prepared using high purity water. Before use, the suspension of MWCNTs was sonicated for 30 min to obtain homogeneous dispersion. The $\mathrm{pH}$ of the solutions being analyzed was adjusted with $0.1 \mathrm{~mol} \mathrm{~L}^{-1} \mathrm{HNO}_{3}$ and $0.1 \mathrm{~mol}$ $\mathrm{L}^{-1} \mathrm{NH}_{3}$. All reagents were dissolved and diluted with high purity water obtained from a Milli-Q system.

\section{Instrumentation}

Wavelength-dispersive X-ray fluorescence (WDXRF) spectrometry. Spectrometer Rigaku ZSX Primus with a rhodium target X-ray tube (max. power $4 \mathrm{~kW}$ ), a LiF analysing crystal and a scintillation counter was used for the measurements. The X-ray tube was operated at $50 \mathrm{kV}$ and $60 \mathrm{~mA}$. The measurements were performed in a vacuum. The net intensities of Se $\mathrm{K} \alpha$ were determined for each sample by the measurement of fluorescent radiation of $\mathrm{Se}$ and the measurement of the continuum close to the peak.

Energy-dispersive X-ray fluorescence (EDXRF) spectrometry. A touch-control S2 RANGER EDXRF system (Bruker AXS, $\mathrm{GmbH}$, Germany) with a Pd X-ray tube (max. power $50 \mathrm{~W}$ ) and an XFLASHTM Silicon Drift Detector (SDD) with a resolution $<129 \mathrm{eV}$ at $\mathrm{Mn} \mathrm{K} \alpha$ was used. The instrument is also equipped with nine primary filters that can be selected for improving measuring conditions for elements of interest. Detailed information about specific features of the S2 RANGER spectrometer can be found elsewhere. ${ }^{29}$ To obtain the most efficient excitation for $\mathrm{Se}(\mathrm{IV})$ determination, an evaluation of different measuring modes ( $\mathrm{kV} /$ primary beam filters) was carried out. In all cases, the intensity was adjusted automatically to obtain a maximum count rate of $100000 \mathrm{cps}$ and the measuring time (200 s) was selected as a trade-off between an acceptable repeatability of measurements and total analysis time. The net intensities of $\mathrm{Se} \mathrm{K} \alpha$ were calculated by subtracting the theoretical background calculated by a polynominal function (Spectra EDX software, 2011 Bruker AXS GMBH).

Loaded filters were placed between two $6.0 \mu \mathrm{m}$-thick Mylar X-ray foils (supplied by Chemplex Industries, Inc., New Cork, USA) mounted in special liquid sample holders which incorporate a snap-on ring at the end of the cell for attachment of thinfilm supports. Afterwards, samples were sealed in the sample holder of the equipment for EDXRF or WDXRF analysis. The blank sample was prepared using the described procedure and high purity water obtained from the Milli-Q system instead of the analyzed solution.

\section{Preconcentration procedure}

The proposed DSPME procedure was as follows: an aliquot of $100 \mathrm{~mL}$ of sample was placed in a $150 \mathrm{~mL}$ beaker. Then, $100 \mu \mathrm{L}$ of $2 \%(\mathrm{~m} / \mathrm{v})$ APDC solution and $200 \mu \mathrm{L}$ of dispersed oxidizedMWCNTs at a concentration of $5 \mathrm{mg} \mathrm{mL}^{-1}$ were added. The $\mathrm{pH}$ of the sample was adjusted to 2 using $0.1 \mathrm{~mol} \mathrm{~L}^{-1} \mathrm{HNO}_{3}$ and $0.1 \mathrm{~mol} \mathrm{~L}^{-1} \mathrm{NH}_{3}$. Subsequently, the solution was stirred at $700 \mathrm{rpm}$ for $5 \mathrm{~min}$. Homogenization was immediately achieved, which promoted the interaction between the Se(Iv)-APDC and oxidized-MWCNTs. The whole volume was passed through a Whatman filter (25 mm diameter) using a filtration assembly (25 mm, Sigma-Aldrich). MWCNTs (with adsorbed metal chelates) collected onto the filter were dried under an IR heater. The calibration samples were prepared using the described DSPME procedure with a series of standard solutions containing $\mathrm{Se}(\mathrm{IV})$ ions.

\section{Preparation of real samples}

Water samples. The mineral water was filtered through a Millipore membrane filter of $0.45 \mu \mathrm{m}$ pore size. In order to determine $\mathrm{Se}(\mathrm{IV})$, the analyte was preconcentrated using the DSPME procedure described above without the reduction step. In the case of the simultaneous determination of $\mathrm{Se}(\mathrm{IV}), \mathrm{Se}(\mathrm{VI})$ 
and total Se, the reduction with hydrochloric acid was performed. Se(IV) was determined in one portion using the proposed procedure, whereas the sum of $\mathrm{Se}(\mathrm{IV})$ and $\mathrm{Se}(\mathrm{VI})$ was determined in the other portion after the reduction of $\mathrm{Se}(\mathrm{vI})$ to $\mathrm{Se}(\mathrm{IV})$ with hydrochloric acid, as described in ref. 19.

Biological samples. $250 \mathrm{mg}$ of the sample was digested in $5.0 \mathrm{~mL}$ of concentrated $\mathrm{HNO}_{3}$. Microwave-assisted digestion of the sample was performed in closed $100 \mathrm{~mL}$ vessels with the maximum pressure of the vessels set to $45 \mathrm{~atm}$. After cooling, the sample was transferred to a $150 \mathrm{~mL}$ beaker and $\mathrm{HNO}_{3}$ was evaporated. The reduction of $\mathrm{Se}(\mathrm{VI})$ to $\mathrm{Se}(\mathrm{IV})$ was performed using hydrochloric acid. Then, Se(IV) was preconcentrated using the DSPME procedure described above.

\section{Results and discussion}

\section{Optimization of preconcentration procedure}

In this paper, trace amounts of Se(IV) ions were preconcentrated using DSPME with MWCNTs as an adsorbent and APDC as a chelating agent. In order to obtain high recovery of the Se ions on MWCNTs, the proposed procedure was optimized for various analytical parameters such as $\mathrm{pH}$, amounts of MWCNTs and
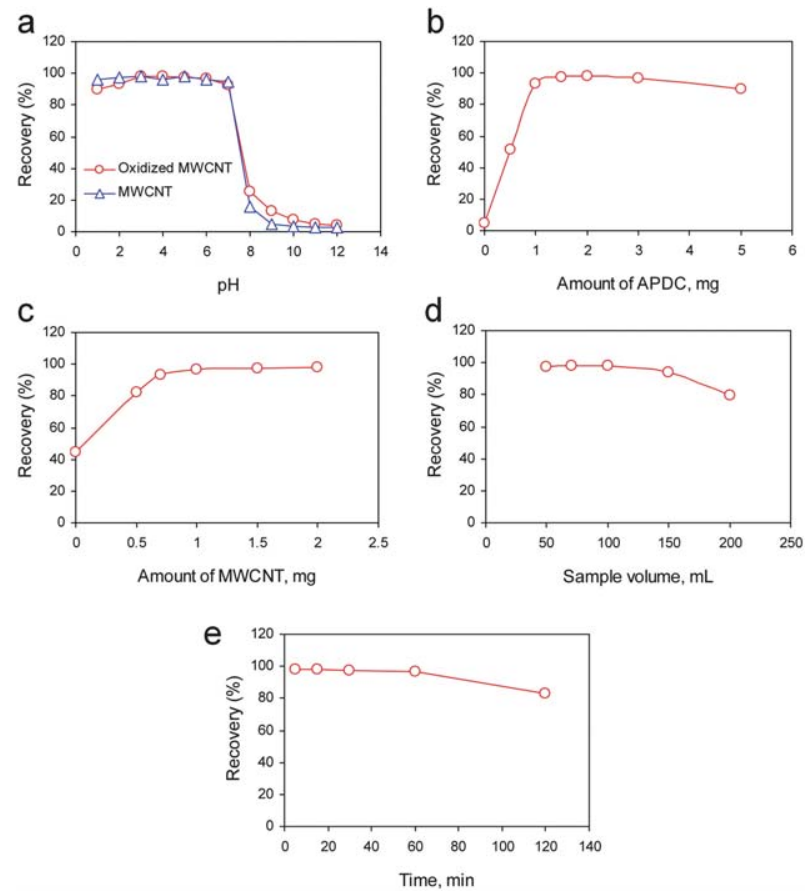

Fig. 1 Optimization of preconcentration procedure: (a) effect of $\mathrm{pH}$ on recovery of $\mathrm{Se}$ (IV) (sample volume $100 \mathrm{~mL}, 50 \mathrm{ng} \mathrm{mL}^{-1}$ of $\mathrm{Se}(\mathrm{IV}), 0.02 \mathrm{mg}$ $\mathrm{mL}^{-1}$ of APDC, $1 \mathrm{mg}$ of MWCNTs, time of stirring $5 \mathrm{~min}$ ); (b) effect of APDC amount (sample volume $100 \mathrm{~mL}, 50 \mathrm{ng} \mathrm{mL}^{-1}$ of $\mathrm{Se}(\mathrm{Iv}), \mathrm{pH}=2,1$ mg of MWCNTs, time of stirring $5 \mathrm{~min}$ ); (c) effect of MWCNTs amount (sample volume $100 \mathrm{~mL}, 50 \mathrm{ng} \mathrm{mL}^{-1}$ of Se(IV), $0.02 \mathrm{mg} \mathrm{mL}^{-1}$ of APDC, $\mathrm{pH}=2$, time of stirring $5 \mathrm{~min}$ ); (d) effect of sample volume (5 $\mu \mathrm{g}$ of Se(IV), $\mathrm{pH}=2,0.02 \mathrm{mg} \mathrm{mL}^{-1}$ of APDC, $1 \mathrm{mg}$ of MWCNTs, time of stirring $5 \mathrm{~min}$ ); and (e) effect of stirring time (sample volume $100 \mathrm{~mL}, 50 \mathrm{ng} \mathrm{mL}^{-1}$ of $\mathrm{Se}(\mathrm{Iv}), \mathrm{pH}=2,0.02 \mathrm{mg} \mathrm{mL}^{-1}$ of APDC, $1 \mathrm{mg}$ of MWCNTs).
APDC, sample volume and time of the sorption process. The obtained results are presented in Fig. 1.

The effect of the sample $\mathrm{pH}$ on the adsorption of $\mathrm{Se}(\mathrm{IV})$ on MWCNTs in the presence of APDC was studied at $\mathrm{pH}$ ranging from 1.0 to 12.0. As can be seen in Fig. 1a, high recoveries can be obtained at the $\mathrm{pH}$ range of 1.0-7.0. A sample $\mathrm{pH}$ of 2.0 was chosen for the subsequent experiments. Fig. 1a shows that the raw- and oxidized-MWCNTs gave similar results. However, the subsequent experiments were performed using oxidizedMWCNTs due to their dispersibility in water samples.

Selenium ions cannot be adsorbed on MWCNTs without a chelating agent. In the presence of APDC, the formation of hydrophobic complexes plays an important role and Se(Iv) can be adsorbed on MWCNTs through van der Waals forces and the hydrophobic interaction. Therefore, an appropriate amount of APDC should be used to ensure the effective complexation of $\mathrm{Se}(\mathrm{IV})$ ions and to obtain high recovery. The effect of the amount of APDC on recoveries was studied in the range of $0-0.05 \mathrm{mg}$ $\mathrm{mL}^{-1}$ (from 0 to $5 \mathrm{mg}$ of APDC in the sample of $100 \mathrm{~mL}$ volume). Fig. 1b shows that high recovery of Se(Iv) was achieved at APDC concentrations of $0.01-0.05 \mathrm{mg} \mathrm{mL}^{-1}$. The subsequent studies were carried out using an APDC concentration of $0.02 \mathrm{mg} \mathrm{mL}^{-1}$.

The amount of the MWCNTs has influence on the contact between the sample solution and the surface of the sorbent and in consequence on the time of adsorption. Therefore, a suitable amount of the MWCNTs is a crucial issue in DSPME. The effect of the amount of MWCNTs on the recovery was investigated in the range of $0-2 \mathrm{mg}$ per $100 \mathrm{~mL}$ of the analyzed solution. The results showed (Fig. 1c) that the recovery increased with the amount of MWCNTs up to $0.7 \mathrm{mg}$. Above $0.7 \mathrm{mg}$ of the sorbent, the recovery remained at the same high level ( $c a .100 \%)$. In general, the quantitative recovery can be obtained if $1 \mathrm{mg}$ of MWCNTs is used for preconcentration of Se(Iv) from $100 \mathrm{~mL}$ sample volume. Such conclusion was confirmed by the experiments performed using various sample volumes. The effect of sample volume on the recovery (Fig. 1d) was investigated by varying the sample volume containing $5 \mu \mathrm{g}$ of Se(Iv) from 50 to $200 \mathrm{~mL}$ using $1 \mathrm{mg}$ of MWCNTs. The results showed that the recovery of $\mathrm{Se}$ (Iv) remained constant within $50-100 \mathrm{~mL}$ of the sample, whereas for the sample volume above $100 \mathrm{~mL}$ the recovery decreased. A sample volume of $100 \mathrm{~mL}$ and $1 \mathrm{mg}$ of MWCNTs were chosen for the subsequent experiments and analysis of real samples.

In this work, trace amounts of Se(IV) were preconcentrated using the DSPME procedure. Therefore, the time of stirring is a measure of the contact time between the sample solution and the MWCNTs. This effect was investigated by varying the time from 5 to $120 \mathrm{~min}$ using $1 \mathrm{mg}$ of MWCNTs and $100 \mathrm{~mL}$ sample with a $\mathrm{Se}(\mathrm{IV})$ concentration of $0.05 \mu \mathrm{g} \mathrm{mL}^{-1}$. As shown in Fig. 1e, time variation in the range of 5-60 min does not influence the adsorption of the Se(IV)-APDC complex onto the surface of MWCNTs. It was found that DSPME using MWCNTs promoted the immediate interaction between the Se(IV)-APDC complex and MWCNTs. This resulted from the fact that MWCNTs were dispersed in the whole volume of aqueous samples. A stirring time of 5 min was chosen for analysis of unknown samples.

Under the optimized experimental conditions described above, the recovery of Se(Iv) was $97 \pm 3 \%$. The relative standard deviation characterizing precision of the method obtained after 
Table 1 Influence of some ions on the recoveries of selenium

\begin{tabular}{|c|c|}
\hline Matrix & Recovery (\%) \\
\hline $\begin{array}{l}50 \mu \mathrm{g} \mathrm{mL}^{-1} \mathrm{Na}(\mathrm{I}), \mathrm{K}(\mathrm{I}), \mathrm{Mg}(\mathrm{II}) \\
250 \mu \mathrm{g} \mathrm{mL}^{-1} \mathrm{Ca}(\mathrm{II})\end{array}$ & $97 \pm 4.5$ \\
\hline $\begin{array}{l}100 \mu \mathrm{g} \mathrm{mL}^{-1} \mathrm{Na}(\mathrm{I}), \mathrm{K}(\mathrm{I}), \mathrm{Mg}(\mathrm{II}), \\
500 \mu \mathrm{g} \mathrm{mL}^{-1} \mathrm{Ca}(\mathrm{II})\end{array}$ & $98 \pm 4.8$ \\
\hline $\begin{array}{l}200 \mu \mathrm{g} \mathrm{mL}^{-1} \mathrm{Na}(\mathrm{I}), \mathrm{K}(\mathrm{I}), \mathrm{Mg}(\mathrm{II}) \\
1000 \mu \mathrm{g} \mathrm{mL}^{-1} \mathrm{Ca}(\mathrm{II})\end{array}$ & $102 \pm 3.8$ \\
\hline $0.5 \mu \mathrm{g} \mathrm{mL}^{-1} \mathrm{Fe}(\mathrm{III}), \mathrm{Al}(\mathrm{III})$ & $98 \pm 2.9$ \\
\hline $1.0 \mu \mathrm{g} \mathrm{mL}^{-1} \mathrm{Fe}(\mathrm{III}), \mathrm{Al}(\mathrm{III})$ & $99 \pm 3.5$ \\
\hline $5.0 \mu \mathrm{g} \mathrm{mL}^{-1} \mathrm{Fe}(\mathrm{III}), \mathrm{Al}(\mathrm{III})$ & $95 \pm 4.2$ \\
\hline $\begin{array}{l}0.1 \mu \mathrm{g} \mathrm{mL}^{-1} \mathrm{Cr}(\mathrm{III}), \mathrm{Co}(\mathrm{II}), \mathrm{Ni}(\mathrm{II}) \\
\mathrm{Cu} \text { (II), } \mathrm{Cd}(\mathrm{II}), \mathrm{Pb}(\mathrm{II}),\end{array}$ & $97 \pm 3.7$ \\
\hline $1 \mu \mathrm{g} \mathrm{mL}^{-1} \mathrm{Mn}(\mathrm{II}), \mathrm{Zn}(\mathrm{II})$ & \\
\hline $0.2 \mu \mathrm{g} \mathrm{mL}^{-1} \mathrm{Cr}(\mathrm{III}), \mathrm{Co}(\mathrm{II}), \mathrm{Ni}(\mathrm{II})$ & $100 \pm 3.3$ \\
\hline $\mathrm{Cu}(\mathrm{II}), \mathrm{Cd}(\mathrm{II}), \mathrm{Pb}(\mathrm{II})$ & \\
\hline $2 \mu \mathrm{g} \mathrm{mL}^{-1} \mathrm{Mn}(\mathrm{II}), \mathrm{Zn}(\mathrm{II})$ & \\
\hline
\end{tabular}

analyzing a series of nine replicates for $5 \mu \mathrm{g}$ of Se(Iv) in $100 \mathrm{~mL}$ was $3.2 \%$.

The effects of common coexisting ions in different types of water such as $\mathrm{Na}$ (I), $\mathrm{K}$ (I), $\mathrm{Mg}$ (II), $\mathrm{Ca}$ (II), $\mathrm{Al}(\mathrm{III}), \mathrm{Fe}(\mathrm{III})$ and some heavy metals on the adsorption of Se(IV)-APDC on MWCNTs were investigated. The recoveries of selenium determined in various amounts of matrix ions are given in Table 1. As can be seen, the major cations which can be present in natural water have no obvious influence on the determination of selenium under the optimized conditions. The chemical interferences from $\mathrm{Fe}(\mathrm{III}), \mathrm{Mn}(\mathrm{II}), \mathrm{Zn}(\mathrm{II}), \mathrm{Co}(\mathrm{II}), \mathrm{Ni}(\mathrm{II})$ and $\mathrm{Cu}(\mathrm{II})$ present in high concentrations were also investigated. Table 2 shows that Se(Iv) can be determined with very good recovery in the presence of $\mathrm{Co}(\mathrm{II}), \mathrm{Ni}(\mathrm{II})$, and $\mathrm{Mn}(\mathrm{II})$. However, the chemical interferences were observed when high concentrations of $\mathrm{Cu}(\mathrm{II}), \mathrm{Fe}(\mathrm{III})$, and $\mathrm{Zn}$ (II) were present in the sample. In these cases, the precipitation of metal hydroxides using $\mathrm{NaOH}$ can be used as an efficient method for complete elimination of the transition metal interferences. ${ }^{6}$ The results obtained after the precipitation of

Table 2 Influence of some ions on the recoveries of selenium using procedures with and without precipitation of metal hydroxides

\begin{tabular}{|c|c|c|c|}
\hline \multicolumn{2}{|l|}{ Matrix } & \multicolumn{2}{|c|}{ Recovery of selenium (\%) } \\
\hline Element & $\mu \mathrm{g} \mathrm{mL}^{-1}$ & Without precipitation & $\begin{array}{l}\text { With precipitation } \\
\text { using } \mathrm{NaOH}\end{array}$ \\
\hline \multirow[t]{3}{*}{$\mathrm{Cu}$} & 1 & $104 \pm 3.2$ & $99 \pm 2.6$ \\
\hline & 5 & $32 \pm 5.4$ & $100 \pm 3.5$ \\
\hline & 10 & $28 \pm 1.8$ & $97 \pm 4.0$ \\
\hline \multirow[t]{3}{*}{ Co } & 0.1 & $98 \pm 3.9$ & - \\
\hline & 1 & $102 \pm 2.9$ & - \\
\hline & 2 & $105 \pm 4.3$ & - \\
\hline \multirow[t]{3}{*}{$\mathrm{Ni}$} & 0.1 & $100 \pm 2.3$ & - \\
\hline & 1 & $96 \pm 3.1$ & - \\
\hline & 2 & $103 \pm 5.0$ & - \\
\hline \multirow[t]{3}{*}{$\mathrm{Fe}$} & 5 & $97 \pm 3.0$ & $98 \pm 4.1$ \\
\hline & 10 & $11.2 \pm 0.7$ & $94 \pm 3.3$ \\
\hline & 30 & $8.6 \pm 0.6$ & $72 \pm 5.4$ \\
\hline \multirow[t]{3}{*}{$\mathrm{Zn}$} & 5 & $95 \pm 3.5$ & $100 \pm 2.3$ \\
\hline & 10 & $93 \pm 2.9$ & $98 \pm 2.7$ \\
\hline & 30 & $35 \pm 1.2$ & $90 \pm 4.6$ \\
\hline \multirow[t]{3}{*}{$\mathrm{Mn}$} & 1 & $95 \pm 2.4$ & - \\
\hline & 5 & $98 \pm 3.7$ & - \\
\hline & 10 & $97 \pm 3.8$ & - \\
\hline
\end{tabular}

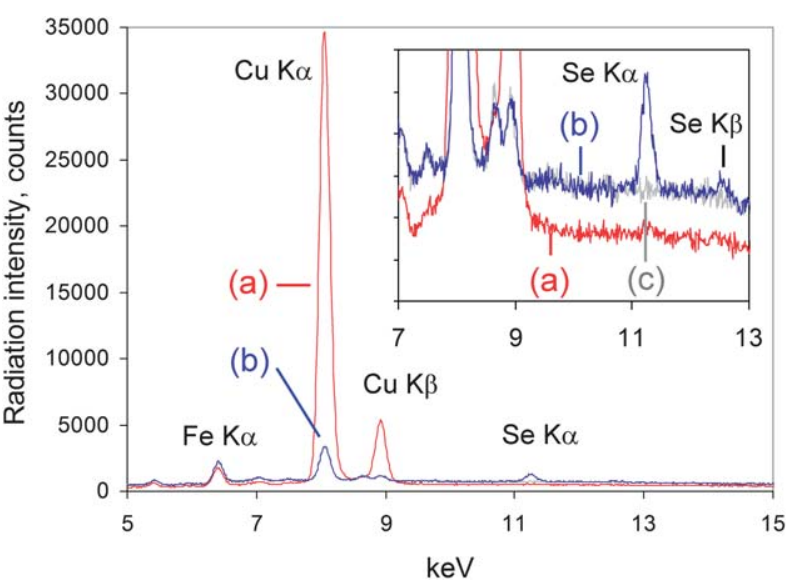

Fig. 2 Spectra of samples containing $50 \mathrm{ng} \mathrm{mL}^{-1}$ of Se(Iv) and $5000 \mathrm{ng}$ $\mathrm{mL}^{-1}$ of $\mathrm{Cu}$ (II): (a) without precipitation of $\mathrm{Cu}(\mathrm{OH})_{2}$, (b) with precipitation of $\mathrm{Cu}(\mathrm{OH})_{2}$, and (c) blank sample.

hydroxides of interfering metal ions are shown in Table 2. Spectra of the samples containing high excess of $\mathrm{Cu}(\mathrm{II})$ are presented in Fig. 2 as an example. As can be seen, the precipitation allows removing $\mathrm{Cu}$ (II) ions from the aqueous sample and simultaneously obtaining a satisfactory signal for Se.

\section{Detection limit and XRF measurements}

The samples were measured using both EDXRF and WDXRF spectrometry. To obtain the best sensitivity and peak/background ratio, an evaluation of different measuring modes $(\mathrm{kV} /$ primary beam filters) was carried out. The linear ranges, correlation coefficients, sensitivities and detection limits (DLs) together with measurement conditions are presented in Table 3. The DLs were calculated from DL $=(3 / k)(R / t)^{1 / 2}$ (where $k$ is the sensitivity of the method, $R$ is the background count rate in counts per second and $t$ is the counting time). As can be seen, WDXRF allows obtaining DLs in the range of $0.13-0.23$ depending on the counting time. In the case of EDXRF, the best DLs can be obtained for $40 \mathrm{kV} / 500 \mu \mathrm{m} \mathrm{Al}$ and $50 \mathrm{kV} / 5 \mu \mathrm{m} \mathrm{Ag}$. However, much better sensitivity was achieved when the primary filter made of $\mathrm{Ag}(5 \mu \mathrm{m})$ and X-ray tube voltage of $50 \mathrm{kV}$ were used. The obtained DLs are below the maximum contaminant level for selenium that might be found in drinking water according to EPA $\left(50 \mathrm{ng} \mathrm{mL}^{-1}\right)^{30}$ and the Polish regulations for bottled water $\left(10 \mathrm{ng} \mathrm{mL}^{-1}\right){ }^{31}$

\section{Analytical application}

The accuracy of the proposed procedure was verified by an analysis of Lobster Hepatopancreas Reference Material (TORT2). Table 4 shows excellent agreement between certified and determined concentrations of selenium. The reliability of the analytical procedure was also examined by an analysis using a water sample spiked with a known concentration of selenium. The sample was spiked with 2.0, 5.0 and $10 \mathrm{ng} \mathrm{mL}^{-1}$ of Se. The results presented in Table 5 show that the recoveries of selenium are reasonable for trace analysis, in the range of $90-104 \%$. The average relative standard deviation (RSD) characterizing precision of the method is $c a .3 \%$ and the average difference between 
Table 3 Measurement conditions, sensitivities and detection limits obtained using the optimized preconcentration procedure

\begin{tabular}{|c|c|c|c|c|c|c|c|}
\hline \multicolumn{5}{|c|}{ Measurement conditions } & $\begin{array}{l}\text { Sensitivity, counts, } \\
\mathrm{mL} \mathrm{s}^{-1} \mu \mathrm{g}^{-1}\end{array}$ & \multicolumn{2}{|l|}{$\mathrm{DL}, \mathrm{ng} \mathrm{mL}^{-1}$} \\
\hline EDXRF & $\mathrm{Pd}$ & 40 & 1.210 & $\mathrm{Al} 500 \mu \mathrm{m}$ & $970 \pm 39$ & 0.10 & 0.06 \\
\hline EDXRF & $\mathrm{Pd}$ & 50 & 0.710 & $\mathrm{Al} 500 \mu \mathrm{m}$ & $941 \pm 48$ & 0.20 & 0.11 \\
\hline EDXRF & $\mathrm{Pd}$ & 50 & 0.591 & Ag $5 \mu \mathrm{m}$ & $1421 \pm 73$ & 0.10 & 0.06 \\
\hline WDXRF & $\mathrm{Rh}$ & 50 & 60 & None & 34529 & 0.23 & 0.13 \\
\hline
\end{tabular}

Table 4 Analysis of certified reference material (TORT-2)

\begin{tabular}{llll}
\hline & $\begin{array}{l}\text { Certified } \\
\text { concentration, } \\
\mu \mathrm{g} \mathrm{g}^{-1}\end{array}$ & $\begin{array}{l}\text { Found, } \\
\mu \mathrm{g} \mathrm{g}^{-1}\end{array}$ & $\begin{array}{l}\text { Accuracy } \\
(\%)\end{array}$ \\
\hline $\begin{array}{l}\text { As (21.6), } \mathrm{Cd}(26.7), \mathrm{Cu}(106), \\
\mathrm{Fe}(105), \mathrm{Mn}(13.6), \mathrm{Ni}(2.5),\end{array}$ & $5.4 \pm 0.2$ & 2.3 \\
$\mathrm{Sr}(45.2), \mathrm{V}(1.64), \mathrm{Zn}(180)$ & \\
$\begin{array}{l}{ }^{a} \text { Matrix elements at concentrations below } 1 \mu \mathrm{g} \mathrm{g}^{-1} \text { are not included in } \\
\text { the table. }\end{array}$
\end{tabular}

Table 5 Determination of total selenium in spiked water samples

\begin{tabular}{lccc}
\hline Water sample & $\begin{array}{l}\text { Added, } \\
\text { ng mL }\end{array}$ & $\begin{array}{l}\text { Found, } \\
\text { ng mL }^{-1}\end{array}$ & $\begin{array}{l}\text { Recovery } \\
(\%)\end{array}$ \\
\hline Water A & 0 & $<\mathrm{DL}$ & \\
& 2.0 & $1.82 \pm 0.05$ & 90 \\
& 5.0 & $5.2 \pm 0.18$ & 104 \\
Water B & 10.0 & $9.6 \pm 0.25$ & 96 \\
& 0 & $<\mathrm{DL}$ & \\
& 2.0 & $1.9 \pm 0.10$ & 95 \\
& 5.0 & $4.7 \pm 0.08$ & 94 \\
& 10.0 & $9.8 \pm 0.22$ & 98 \\
\hline
\end{tabular}

Table 6 Determination of Se(Iv) and $\mathrm{Se}(\mathrm{vI})$ in spiked water samples

\begin{tabular}{|c|c|c|c|c|c|}
\hline \multicolumn{2}{|c|}{ Added, $\mathrm{ng} \mathrm{mL}^{-1}$} & \multicolumn{2}{|c|}{ Found, ng $\mathrm{mL}^{-1}$} & \multicolumn{2}{|c|}{ Recovery (\%) } \\
\hline $\mathrm{Se}(\mathrm{IV})$ & $\mathrm{Se}(\mathrm{VI})$ & $\mathrm{Se}(\mathrm{IV})$ & $\mathrm{Se}(\mathrm{VI})$ & $\mathrm{Se}(\mathrm{IV})$ & $\mathrm{Se}(\mathrm{vI})$ \\
\hline 0 & 0 & $<\mathrm{DL}$ & $<\mathrm{DL}$ & - & - \\
\hline 50.0 & 0 & $48.3 \pm 2.2$ & $<\mathrm{DL}$ & 96.6 & - \\
\hline 0 & 50.0 & $<\mathrm{DL}$ & $47.6 \pm 4.5$ & - & 95.2 \\
\hline 50.0 & 50.0 & $51.9 \pm 2.9$ & $48.7 \pm 5.6$ & 103.8 & 97.4 \\
\hline
\end{tabular}

added and found concentration is $c a$. $5 \%$. Therefore, the results demonstrate that the proposed method is suitable for the analysis of real water samples. It is worth emphasizing that according to Polish regulations on natural mineral water, branch water and bottled water, the precision and the accuracy of the method for selenium determination should not be worse than $10 \% .{ }^{31}$ The proposed method can also be applied to the simultaneous determination of $\mathrm{Se}(\mathrm{IV}), \mathrm{Se}(\mathrm{vI})$ and total Se. The recoveries were also examined by spiking water samples with various Se species. $\mathrm{Se}(\mathrm{IV})$ was determined in one portion using the proposed procedure, whereas the sum of $\mathrm{Se}(\mathrm{IV})$ and $\mathrm{Se}(\mathrm{vI})$ was determined in the other portion after reduction of $\mathrm{Se}(\mathrm{vI})$ to $\mathrm{Se}(\mathrm{IV})$ with hydrochloric acid. The concentration of $\mathrm{Se}(\mathrm{VI})$ was calculated as the difference. The results presented in Table 6 show that $\mathrm{Se}(\mathrm{IV}), \mathrm{Se}(\mathrm{VI})$ and total
Se can be successfully determined in water samples by the proposed method.

\section{Conclusion}

The proposed procedure based on DSPME using MWCNTs as a sorbent can be successfully applied in the determination of trace amounts of Se(Iv) with very good recovery and precision. MWCNTs were dispersed in aqueous samples, which promoted the immediate interaction between the Se(Iv) chelate and MWCNTs. Such strategy allows shortening the time of sample preparation in comparison with the classical SPE. Moreover, the MWCNTs with adsorbed Se(Iv)-APDC complex are measured directly using XRF spectrometry without the necessity of analyte elution. The prepared samples can be stored and measured many times. The obtained DL $\left(0.06 \mathrm{ng} \mathrm{mL}^{-1}\right)$ is below the maximum contaminant level for selenium that might be found in drinking water according to EPA $\left(50 \mathrm{ng} \mathrm{mL}^{-1}\right)$ and the Polish regulations for bottled water $\left(10 \mathrm{ng} \mathrm{mL}^{-1}\right)$. Therefore, the proposed method is suitable for the analysis of real water samples. Moreover, it can be applied for the determination of selenium in biological samples and to selenium speciation due to high and low stability of APDC complexes with $\mathrm{Se}(\mathrm{IV})$ and $\mathrm{Se}(\mathrm{vI})$, respectively.

\section{Acknowledgements}

This work was supported by the Spanish National Research Program (project ref. CGL2010-22168-C3-01).

\section{References}

1 C. Thiry, A. Ruttens, L. De Temmerman, Y.-J. Schneider and L. Pussemier, Food Chem., 2012, 130, 767-784.

2 B. D. Wake, A. R. Bowie, E. C. V. Butler and P. R. Haddad, $\operatorname{Tr} A C$, Trends Anal. Chem., 2004, 23, 491-500.

3 K. Pyrzynska, Microchim. Acta, 2002, 140, 55-62.

4 P. C. Uden, Anal. Bioanal. Chem., 2002, 373, 422-431.

5 A. R. Kumar and P. Riyazuddin, Int. J. Environ. Anal. Chem., 2007, 87, 469-500.

6 P. Pohl and W. Zyrnicki, Anal. Chim. Acta, 2002, 468, 71-79.

7 P. Pohl, TrAC, Trends Anal. Chem., 2004, 23, 87-101.

8 L. Zhang, Y. Morita, A. Sakuragawa and A. Isozaki, Talanta, 2007, 72, 723-729.

9 D. Leyva, J. Estevez, A. Montero and I. Pupo, J. Radioanal. Nucl. Chem., 2012, 291, 699-705.

10 C. Yu, Q. Cai, Z.-X. Guo, Z. Yang and S. B. Khoo, J. Anal. At. Spectrom., 2004, 19, 410-413.

11 M. Mulugeta, G. Wibetoe, C. J. Engelsen and W. Lund, J. Anal. At. Spectrom., 2010, 25, 169-177.

12 K. O. Saygi, E. Melek, M. Tuzen and M. Soylak, Talanta, 2007, 71, $1375-1381$.

13 C.-Y. Lu, X.-P. Yan, Z.-P. Zhang, Z.-P. Wang and L.-W. Liu, J. Anal. At. Spectrom., 2004, 19, 277-281. 
14 B. Chen, B. Hu and M. He, Rapid Commun. Mass Spectrom., 2006, 20, 2894-2900.

15 A. Bidari, E. Z. Jahromi, Y. Assadi and M. R. M. Hosseini, Microchem. J., 2007, 87, 6-12.

16 E. M. Martinis, L. B. Escudero, P. Berton, R. P. Monasterio, M. F. Filippini and R. G. Wuilloud, Talanta, 2011, 85, 21822188.

17 E. Marguí, G. H. Floor, M. Hidalgo, P. Kregsamer, G. Román-Ross, C. Streli and I. Queralt, Anal. Chem., 2010, 82, 7744-7751.

18 R. Sitko, K. Kocot, B. Zawisza, B. Feist and K. Pytlakowska, J. Anal. At. Spectrom., 2011, 26, 1979-1985.

19 L. Xia, B. Hu, Z. Jiang, Y. Wu, R. Chen and L. Li, J. Anal. At. Spectrom., 2006, 21, 362-365.

20 K. Urbánková, M. Moos, J. Machát and L. Sommer, Int. J. Environ. Anal. Chem., 2011, 91, 1077-1087.

21 Q. Liu, Cent. Eur. J. Chem., 2010, 8, 326-330.
22 Y.-K. Tsoi and K. S. Y. Leung, J. Chromatogr., A, 2011, 1218, 21602164.

23 C. Xiong, M. He and B. Hu, Talanta, 2008, 76, 772-779.

24 T.-S. Lin, J. Hazard. Mater., 2007, 149, 80-85.

25 S. Arpadjan, L. Vuchkova and E. Kostadinova, Analyst, 1997, 122, 243-246.

26 J. Chwastowska, W. Skwara, J. Dudek, E. Sterlińska and L. Pszonicki, Chem. Anal., 2007, 52, 253-263.

27 K. Pyrzynska, TrAC, Trends Anal. Chem., 2010, 29, 718-727.

28 R. Sitko, B. Zawisza and E. Malicka, TrAC, Trends Anal. Chem., 2012, 37, 22-31.

$29 \mathrm{http}: / /$ www.bruker-axs.com/s2_ranger.html, Retrieved 2012-04-10.

$30 \mathrm{http}: / /$ water.epa.gov/drink/contaminants/index.cfm, Retrieved 201204-10.

31 The Health Minister's Regulation, Dz.U.04.120.1256 (The Official Journal of Law 04.120.1256). 